JFTH, Vol. 13, Issue 2, (2016)

ISSN: 2314-7024

\title{
Historic Cairo in the Era of Augmented Reality: OpPortunities AND ChallengeS
}

\author{
Moataz Ahmed Marie \\ Assistant Professor, Tourism Guidance Department \\ Faculty of Tourism and Hotels, University of Sadat City \\ Heba Salah Zaki \\ Assistant Professor, Tourism Studies Department \\ Faculty of Tourism and Hotels, University of Sadat City
}

\begin{abstract}
Currently, it became necessary for many cultural heritage sites to use modern technologies to remain competitive and attractive. Augmented Reality (AR) technology has been recommended to adopt in cultural heritage sites due to its role in attracting visitors, providing them with information, enhancing their experiences and learning in an enjoyable way. Therefore, the aim of this study is to explore the current situation of implementing AR in Historic Cairo as one of the famous Islamic heritage sites in Egypt. Based on judgmental sample, the primary data has been collected using qualitative semistructured interviews with the representatives of key organizations that are responsible for the Egyptian heritage sites. The findings of the practical study revealed that until now, none of the archeological sites in Historic Cairo implementing AR technology-although its potential benefits- because of some challenges. Finally, the current study has been concluded by important suggestions that could encourage the implementation of AR technology at Historic Cairo.
\end{abstract}

Keywords: Augmented Reality, cultural heritage sites, Historic Cairo.

\section{Introduction}

In recent years, technology has become an essential part of our everyday life (Cranmer et al., 2016). It has a great effect on the people's lifestyle, as well as their learning and working methods (Fritz et al., 2005). It is also helping individuals to interactively deal with the surrounding environments through using different multimedia technologies (Deliyiannis \& Papaioannou, 2014). Therefore, it is became very important for many tourist destinations to adopt new technologies to remain competitive and attractive (Yovcheva et al., 2013; Han et al., 2014), as well as, providing tourists with unique experiences and making the destination more accessible and interesting for both inhabitants and tourists (Buhalis \& Amaranggana, 2014).

One of the latest technological developments is Augmented Reality (AR), a digital system that uses a camera of a computer, a mobile phone or other devices to capture an image of the surrounding environment, then merging it with a computer generated data such as text, image, and video 
(Kounavis et al., 2012). AR is characterized by overlaying virtual data to the real environment instead of replacing it (Azuma, 1997). AR technology can be used in many fields, such as: education, cultural heritage, entertainment, medicine, marketing, architecture, navigation, and geographical field work (Höllerer \& Feiner, 2004; Kounavis et al., 2012). Due to its importance, it is also utilized within tourism sector, various studies (Fritz et al., 2005; Kounavis et al., 2012; Casella \& Coelho, 2013; Yovcheva et al., 2013; Han et al., 2014; tom Dieck \& Jung, 2015) demonstrated AR in the tourism field. The utilization of AR technology in the tourism field can help upgrading the tourists' knowledge, improve their awareness and augment their experiences, as well as, helping them to be better informed (Kounavis et al., 2012). Besides, AR can help tourist institutions and specialists to attract tourists through using attractive multimedia content and mobile applications (Fritz et al., 2005).

In cultural heritage field, AR can help introducing the cultural heritage sites in a better image by communicating the history hidden behind the archaeological sites and sharing the architectural and artistic features of these sites (Zaibon et al., 2015). As a result, AR has the ability to provide tourists with an enjoyable visit and obtain valuable information in an interactively and interesting way (Pendit et al., 2014). However, contrary to anticipations, AR hasn't been actively utilized, because of its newness; it seems to be slower than expected (Chung et al., 2015).

Egypt has numerous cultural heritage sites. Nine of these heritage sites have been registered by UNESCO as world heritage sites, Historic Cairo is considered one of these sites (whc.unesco.org). It gained its importance and fame because it represents the religious life and history of Cairo (Antoniou, 2009). It includes several Islamic architectural monuments dating back to various Islamic eras such as: mosques, religious schools (Madrasas), public fountains (Sabils), public baths (Hammams), palaces and houses (Antoniou, 2009). It also has many historical streets and old dwellings that show the different forms of Egyptian human settlement and traditions during the middle ages (Warner, 2005).

As a result of the special nature of Historic Cairo, AR could be helpful for enhancing the users' interaction with the site (Mohd et al., 2015). It also helps personalizing the tour according to visitors' needs and anticipations, leading to a more prominent and unforgettable trip (Sparacino, 2002). Therefore, the current research aiming at exploring the current situation of implementing AR as an interpretive tool in Historic Cairo as one of the most famous Islamic Cultural Heritage Sites in Egypt. An essential part of implementing any new technology is to understand the perspective of responsible key organizations and users. The user's acceptance and intention to use AR are widely explored (Chung et al., 2015; tom Dieck \& Jung, 2015), however, the studies attempt to understand the implementation of AR from the perspective of concerned local authorities are scarce (Cranmer et al., 2016). In spite of the limited number of researches, they show an affirmative attitude toward AR and realize its potential as an important tool for explanation and education (Casella \& Coelho, 2013).

Because of the modernity of this research area, this is an exploratory study, permitting the identification of main topics, enhances understanding and highlights topics that need further research (Cranmer et al., 2016). Therefore, this study will investigate the current literature of AR in tourism and cultural heritage sites. To fulfill the next phase of the research, semi-structured interviews were held with key representatives of organizations that are responsible for the Egyptian heritage sites to clarify whether AR has been adopted in the Egyptian Islamic cultural heritage sites or not, the 
importance of this new technology for the Egyptian Islamic cultural heritage sites and the key challenges that facing the implementation of AR from the perspective of responsible key organizations. The findings of this research and the issues from the literature shed light on a number of implications for practitioners.

\section{Literature Review Augmented Reality (AR)}

With the emergence of Augmented Reality (AR), many efforts have been done to introduce an appropriate definition. Azuma et al. (1997), defined AR as a system that has three main features: (a) combines real and virtual objects, (b) runs interactively and in real time and (c) registered in 3D. Consequently, AR enhances the real environment by computer-generated content (Hyun et al., 2009). These computer-generated data may be text, video, audio or GPS data (Kounavis et al., 2012). AR merges real and computer-generated information in a real environment, interactively and in real time, where the virtual and physical objects coexist in the same space (Höllerer \& Feiner, 2004; van Krevelen \& Poelman, 2010). Therefore, the user can see the virtual object as a part of the real environment (Butchart, 2011).

The new developments in computer graphics and wireless, as well as, the spread of mobile phone usage facilitate the implementation of AR on smart-phones and tablets (Azuma et. al, 2001; Pendit et al., 2014). Based on these advanced technologies, AR has been developed quickly in different fields as: education, entertainment, cultural heritage, construction, tourism, marketing, architecture, navigation and geographical field work (Höllerer \& Feiner, 2004).

Until recently, Virtual Reality (VR) technologies were one of the most prominent technologies (Fritz et al., 2005). The main idea of VR is to create an artificial world and totally immerses users inside a computer-generated 3D environment - called a virtual environment (VE) - without seeing the real world around them (Guttentag, 2010; Aziz \& Siang, 2014). Thus, although the popularity of VR application, the main disadvantage of it is that there is no relationship between the user and the real world (Fritz et al., 2005). Subsequently, Augmented Reality technologies are becoming increasingly popular, because it augments the real world instead of replacing it and allows the user to see the real world enhanced with two-dimensional (2D) or 3D images overlapped to his field of view (Fritz et al., 2005).

According to the Milgram's reality-virtuality continuum (Figure 1), AR lies among the virtual environment and the real environment (Milgram et al., 1994).

\section{Figure (1) Milgram's Reality-Virtuality Continuum}

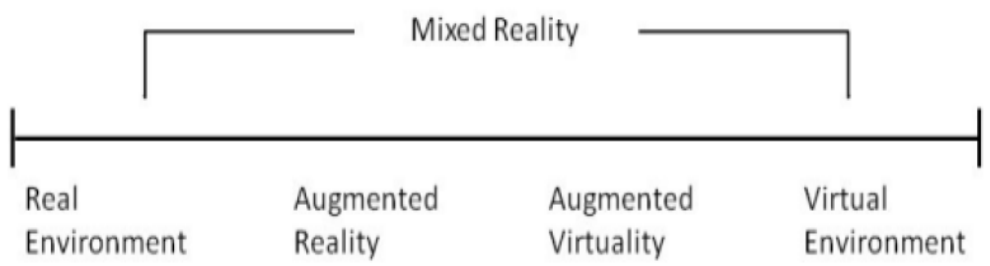

Source: Milgram et al., 1994: 288 
The previous figure shows the differences between real environment (real world objects), virtual environment (means that all objects are virtual), augmented virtuality (where virtual environment is augmented by real objects), and augmented reality (that refers to the real world objects which are augmented by virtual ones) (Rabbi et al., 2013).

As shown in the previous figure, AR is considered one part of the broader concept of mixed reality, at the same time; it is also called mixed reality because it merges virtual information with the real environment (Choi \& Choi, 2014).

The key components needed to build a simple AR system are: a camera, a computer, and a display (Abboud, 2014). As shown in (Figure 2) the camera records the real environment surrounding the user (capturing), then the computer permits the AR system to augment the real image with virtual objects (tracking module) and adds a virtual scene on the camera image (rendering module). Finally, the result displayed as a mix of both real objects and virtual ones (Abboud, 2014).

\section{Figure (2) Flowchart for a simple AR system setup}

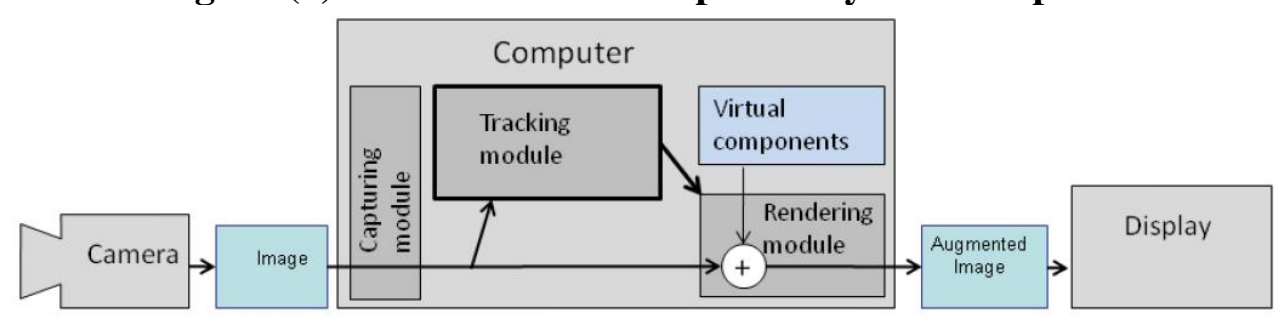

Source: Abboud, 2014: 38

\section{AR in Tourism}

Various researches (Fritz et al., 2005; Kounavis et al., 2012; Casella \& Coelho, 2013; Yovcheva et al., 2013; Han et al., 2014; tom Dieck \& Jung, 2015) explained AR in the tourism field. Fritz et al. (2005) illustrated a visualization system based on augmented reality in tourism field and proved that AR visually enhances the real scene. While, Kounavis et al. (2012) explained the technical sides of mobile AR, showing various mobile AR applications in tourism and its role in enhancing tourists' experiences. Yovcheva et al. (2013) also clarified the smartphone AR for tourism and focused on design sides like the interface, displays, and visualizations, in addition to determining the main features of $\mathrm{AR}$ as the medium of the tourist experience. Casella and Coelho (2013) proved the usefulness of AR technologies for understanding cultural heritage tourism. In addition, Han et al. (2014) identified the tourists' requirements for developing an AR application in urban heritage such as accessing destination information, design interfaces, reviews of other people, multi-lingual aspect, and easy navigation. tom Dieck and Jung (2015) proposed an AR acceptance model in the context of urban heritage tourism; this model includes seven dimensions (information quality, system quality, costs of use, recommendations, personal innovativeness, risk and facilitating conditions). Finally, Chung et al. (2015) proved that technology readiness (TR), visual appeal and facilitating conditions had a significant effect on intention to use AR and intention to visit a heritage site. Despite these various studies and potentials of AR, yet the usage of AR in tourism is still a new issue (Han et al., 2014) 
In tourism, $\mathrm{AR}$ is a good opportunity for organizations and destinations to augment the tourists' experiences via visualization of related information (Leue et al., 2014). Fritz et al. (2005) also assured that AR applications are specially valuable in tourism, because they give tourists the chance to know more about surrounding environment in a way that increase their experience. AR can enhance the tourist awareness through merging information with the real world objects (Yovcheva et al., 2013). It facilitates the creation of a more dynamic interaction among tourists and surrounding environment through using a mobile device (Mohd et al., 2015).

Due to the AR role in enhancing the tourist experience, it has been considered to be of high potential for tourism (Fritz et al., 2005). It has been recognized that tourists are persons who have a little knowledge of the surrounding environment, therefore, such a location-based device, that can be utilized to know information in the real environment, would extremely benefit the tourism industry (Han et al., 2014). The AR application not only able to determine the user's location, but also provides required information of the area that may be useful such as: hotels, restaurants, museums, entertainment, the city's nightlife and sightseeing (Höllerer \& Feiner, 2004; Kounavis et al., 2012). Tourists can simply point the camera of their phones at a specific restaurant, shop, or landmark, then the information about this area such as work hours, directions or comments, shows on the mobile's screen as graphics floating above the image of the site (Anuar, 2013).

AR application also has the ability to provide an interesting tour via the combination of high quality, new and motivating information (Leue et al., 2014). It enables tourists to recognize an unknown area and discover old heritage sides or monuments in a different and interesting style (Leue et al., 2014). Kounavis et al. (2012) introducing a number of mobile AR applications that designed specifically for tourist purposes such as: Tuscany+, Augmented Reality for Basel, Dublin and Urban Sleuth. These applications works as a digital tourist guide, that aim at getting information from online sources, such as Wikipedia, Google Places and the region's official portal. Through these applications, the real world mixed with the virtual, and the user can retrieve location-based information on nearby places in different languages (Kounavis et al., 2012).

\section{AR in Cultural Heritage Sites}

The rise of modern technologies and internet has a great impact on tourism (Cranmer et al., 2016), which led to the change of classical distribution methods (Buhalis et al., 2003). As well as helping the re-design of different techniques and applications in the field of cultural heritage such as AR which became a more acceptable and worthy technological tool (Chung et al., 2015). Currently, digital technologies have been already used in Museums and art galleries for preserving and exploring Arts and Cultural Heritage (Fritz et al., 2005). However, with the emergence of cultural park concept, AR technologies became more important for the virtual reconstruction of historical monuments and helping archaeologists or historians to reproduce on site historical and archaeological areas as they were in their great prosperity era (Fritz et al., 2005).

At the present time, tourists' needs have been changed because they want to enhance their knowledge through using new and unconventional tools (Zaibon et al., 2015). Therefore, AR can be used in the cultural heritage field as a modern way to supply information (Seo et al., 2011). Cultural heritage sites are full of various traditional information sources that can help in increasing the tourist culture and 
learning experience such as: signs, maps, books and pamphlets (Seo et al., 2011; Zaibon et al., 2015). However, all these conventional sources are not reactive and enjoyable for tourists, because they want to broaden their knowledge during their visit (Seo et al., 2011; Zaibon et al., 2015). So, AR application is considered a perfect chance for communicating the history of the site, sharing the site attractions and encourages tourists to visit the site, learn and entertain (Zaibon et al., 2015).

There are a number of projects that have been performed for applying AR in cultural heritage sites, such as: The Intelligent Tourism and Cultural Information through Ubiquitous Service (iTacitus) (Zoellner et al., 2007), GEIST project (Kretschmer et al., 2001), the Mobile Augmented for Cultural Heritage (MARCH) project (Choudary et al., 2009) and finally Augmented Reality based-Cultural Heritage On-site Guide (ARCHEOGUIDE), which presents augmented reality tours of heritage sites using outdoor tracking, mobile computing, 3D visualization, and $\mathrm{AR}$ techniques to reinforce information display and mimics ancient life (Vlahakis et al., 2001). All previous projects enable tourists to explore the heritage sites by overlaying of different types of computer generated data (Audio, Video or 3D virtual model) on the real environment. These projects also presented the possible benefits that can be achieved as a result of using AR at cultural heritage sites which could be used in a similar way in historic Cairo to achieve the same benefits.

\section{Benefits of adopting AR}

Despite the modernity of AR in the field of cultural heritage, some studies (Sparacino, 2002; Fritz et al., 2005; Wagner et al., 2005; Kounavis et al., 2012; Linaza et al., 2012; Fino et al., 2013; Mohd et al., 2015) largely recognized the opportunities and advantages of this emerging technology in the field of cultural heritage tourism for both tourists and tourism destinations.

Firstly, in relation to tourism destinations, AR technology has been considered as a major potential tool for expending and augmenting the value of cultural heritage sites, because it doesn't replace the real world but gets its contents better via adding virtual elements to an object's actual scene (Fino et al., 2013). Moreover, AR has the ability to reinforce the interpretation of the surrounding environment (Wagner et al., 2005), which led to improve the interaction with the tourism destination (Mohd et al., 2015).

Linaza et al. (2012) proved that AR has the ability to excite the users' interest on the tourism destination because the use of AR makes the information more interactive. As a result, AR helps the familiar and traditional heritage sites to be more attractive than usual (Linaza et al., 2012). It provides new chances and kinds of interactions with the user (Fino et al., 2013). Mohd et al., (2015) reported that AR system can play a significance role in increasing the attractiveness of the tourism destination. Based on the previous benefits, AR has the ability to create a value, increase the competitiveness, tourist's number and earnings (Cranmer, 2016).

Secondly, in relation to tourists, AR application can work as a tourist guide, which provides users with only information upon request and suitable for their needs (Garcia-Crespo et al., 2009). So, it has the ability to personalize the tour according to visitors' needs and anticipations, leading to a more prominent and unforgettable trip (Sparacino, 2002). Further to this, these applications help tourists to learn informally in an enjoyable way at cultural heritage site because of using new and unconventional methods (Pendit \& Zaibon, 2014). It should be mentioned that such technology not 
only has the ability to enhance the users' interaction with tourism destination, but also to augment the communication between users each other (Wagner et al., 2005). Kounavis et al. (2012) mentioned that users prefer expressing their opinions with each other on the digital information that shown on the monitor of the device, which can be interpreted through sharing of information. Therefore, AR can provide more added values to users by enhancing the contact between each other and sharing their experiences (Linaza et al., 2012). As a result, AR application is deemed to be a social application, because it facilitates the social interaction among users accessing it (Kounavis et al., 2012).

Finally, AR technology is not only able to make tourists' movement easier, but also enhances the visitors' attention on the visited sites (Mohd et al., 2015). Moreover, it encourages visitors to explore the destination and see it from a different perspective (Fritz et al., 2005).

\section{Challenges of adopting AR}

In spite of the numerous benefits that AR achieved for tourists and cultural heritage sites, it still not being widely and effectively utilized, and its adoption has been gone slower than expected (Chung et al., 2015). Currently, only few cultural heritage sites are taking the advantages of the full potential of AR because of many challenges (Cranmer et al., 2016). Abboud (2014) divided the challenges of AR into three categories: technical challenges, human factors and financial limitations.

In relation to technical challenges, the major emphasis is on tracking system (Mohd et al., 2015). As $\mathrm{AR}$ is merging the computer generated data with the real world (Abboud, 2014), consequently, it needs effective tracking systems such as Global Positioning System (GPS) to accurately determine the user's location (Azuma et al., 2001). Such technological systems are crucial in registering the factors of the real environment and augmenting it with the digital data (Azuma et al., 1997; Höllerer \& Feiner, 2004; Rabbi et al., 2013; Mohd et al., 2015). In addition, applying the AR system in the tourism sector usually requires an internet connection, which is clearly possible through Wi-Fi or $3 \mathrm{G}$ (Kounavis et al., 2012). Nevertheless, not all cities or tourist sites are completely covered with Wi-Fi networks offering free internet access and $3 \mathrm{G}$. Besides the data roaming costs are still expensive for numerous tourists, especially for younger age (Kounavis et al., 2012).

In relation to human factors, resistance to change is considered a great barrier (Abboud, 2014). The acceptance and dependence on such unfamiliar technologies will face initial resistance, because a great number of tourists still prioritize the traditional information sources such as books (Pang et al., 2006; Han et al., 2014). The lack of knowledge how to implement and embrace such new technology is considered another barrier (Cranmer et al., 2016).

Finally, the challenges related to financial limitations, the shortage of enough funding opportunities is considered a major barrier for many tourism destinations (Fritz et al., 2005). Implementing AR system will need extra costs to provide the sites with the needed equipment (Abboud, 2014).

Regardless of the previous challenges, AR will become an important technological tool in tourism industry in the near future, because of its feasible usefulness that can be utilized in both indoor and outdoor environments (Fritz et al., 2005). Therefore, many tourism destinations should develop continuous investment into such new technologies to remain competitive and attractive (Fritz et al., 2005). 


\section{AR and Historic Cairo}

Historic Cairo is considered one of the most famous and important cultural heritage sites in the Islamic world, because it has a great historical and archaeological value (Antoniou, 2009). Its history dates back to the $\left(4^{\text {th }}\right.$ cen. H/ $10^{\text {th }}$ cen. A.D.) when it was founded by Jawhar al-Saqali to be a capital of the Fatimids in Egypt. Then, it witnessed its golden age in the field of Islamic architecture and art at the Mamluk era $\left(7^{\text {th }}-10^{\text {th }}\right.$ cen. H/ $13^{\text {th }}-16^{\text {th }}$ cen. A.D.) (Warner, 2005). It includes a great number of Islamic monuments dating back to various Islamic eras, such as: mosques, madrasa, sabils and kuttabs, khans, palaces, houses, mausoleums, walls and gates (Antoniou, 2009). As a result of its historical and archaeological importance, Historic Cairo was inscribed on as a World Heritage Site in 1979 by UNESCO (whc.unesco.org).

Historic Cairo is a huge and wide cultural heritage site, so that it becomes more difficult for tourists to recognize all the area and identify which archeological site is more important than the other (Zaibon et al., 2015). Many tourists believe that they should leave the site when they want to have more information (Fritz et al., 2005). Therefore, AR could help in solving this problem, because it provides users with information in the real time without separating them from the real world (Vlahakis et al, 2001).

\section{Methodology}

Because of the modernity of this research area, this is an exploratory study, permitting the identification of main topics, enhances understanding and highlights topics that need further research (Cranmer et al., 2016). This research adopts the qualitative approach that enables researchers to get deeper understanding of the individual's views. It also allows informants to describe their experiences and introduce concepts of importance from their perspective and in their own words, rather than adhering to a framework that has been imposed by the researcher (Altinay \& Paraskevas, 2008).

This study used semi- structured interviews as data collection instrument. This interview technique is used to find out what is happening, seek new insights, identify general patterns and understand the relationship between variables (Altinay \& Paraskevas 2008:113). Interviews were held in August and September 2016.

Based on a purposive or judgmental sample, the field study was conducted with (14) semi-structured interviews with representatives of the key organizations that concerned and responsible for the Egyptian Islamic heritage sites (The Supreme Council of Antiquities, the Center for Documentation of Cultural and Natural Heritage (Cult Nat), the General Department of Historic Cairo in Ministry of Antiquities, Sector of Islamic and Coptic Monuments, Urban Regeneration project for Historic Cairo (URHC) ). Purposive sampling is important when the researcher wants to describe a phenomenon or develops something about which only a little is known (Kumar 2014:244). The purposive sampling based on the researcher's judgment as to who can provide the best data which achieve the study's aim (Kumar 2014). Sixteen (16) potential interviewees were contacted, out of which (14) were actually conducted. The selected interviewees were considered experts and the most knowledgeable persons in their field to provide us with suitable information that necessary to develop an understanding of the problem and provide recommendations to encourage the adoption of this new technology in Islamic cultural heritage sites. 
The interview guide consisted of (8) open ended questions. The first two questions collected data about the current position of respondents and years of experience. The third question asked respondents about their opinions on the use of technology in Islamic cultural heritage sites. The fourth question asked respondents about their level of familiarity with AR technology. The fifth question inquired about the current technologies that used in Historic Cairo. The sixth and seventh questions dealt with the respondents' opinions for the benefits and drawbacks of using AR in Historic Cairo. The last question asked respondents about the challenges that may face the implementation of AR in Historic Cairo.

\section{Data analysis}

The current positions of interviewees were as follows: Managers-Executive, Department Managers, IT Managers, Archaeologists, Consultants, Tour guides. In relation to the years of experience, nearly all interviewees have long experience in their field (more than 5 years).

\section{* The importance of using technology in cultural heritage sites}

Nearly all interviewees assured the great importance of using new technologies in cultural heritage sites to remain attractive and competitive, in addition to the role of these new technologies in communicating the history of these heritage sites and preserving them. One interviewee stated that "such new technologies are extremely important for learning. The current tourists -especially the youngsters- became more interested in technology. As a result, tourists are increasingly using smart phones and tablets to create more memorable trips, search information and communicate with other individuals online. So these technologies help them to learn in a different way". Other interviewee mentioned that "the majority of heritage sites all over the world are now using technology to attract more tourists and encourage revisits". One interviewee added that "using technology in heritage site makes these sites more up to date".

As mentioned above, the majority of respondents confirmed the importance of using technology in Islamic heritage sites and agreed that technology should be integrated in these sites. However, one interviewee was completely objected to the use of technology, because of the spiritual nature of these sites.

Table 1: The importance of using technology in Islamic heritage sites

\begin{tabular}{|l|l|}
\hline $\begin{array}{l}\text { Respondent's opinion about the importance of } \\
\text { using technology in Islamic heritage sites }\end{array}$ & $\begin{array}{l}\text { Number of } \\
\text { interviewees }\end{array}$ \\
\hline Prefer using technology & $13(93 \%)$ \\
\hline Objected to the use of technology & $1 \quad(7 \%)$ \\
\hline
\end{tabular}

\section{* Level of familiarity with AR}

Five of interviewees indicated that they were extremely familiar with AR, while five were moderate familiar with AR, and four were unfamiliar with AR. 
Table 2: Respondent's familiarity with AR technology

\begin{tabular}{|l|c|}
\hline \multicolumn{1}{|c|}{ Level of familiarity with AR } & Number of interviewees \\
\hline Extremely familiar & $5(36 \%)$ \\
\hline Moderate & $5(36 \%)$ \\
\hline Unfamiliar & $4(28 \%)$ \\
\hline
\end{tabular}

\section{* The current technologies that have been used in Historic Cairo}

Interviewees assured that Historic Cairo has a website, in addition to using VR for some archaeological sites. GPS is also available in Historic Cairo. Some interviewees added that "GPS sometimes give inexact information". All respondents assured that "the free Wi-Fi service is not available in Historic Cairo".

Respondents from Cult Nat added that "the Cult Nat center used IT for heritage in various forms such as:

- (Cult Rama): they used multimedia and VR technology to create the (Cult Rama) show. This show is available in three languages and takes the audience into a historical journey starting from the Pharaonic era, passing by Coptic and Islamic eras, and ending by the modern age.

- Database Management Technology: Cult Nat center has a treasure of heritage documentation data in different forms (i.e. databases, images, videos, 3D models, documents, etc.). They used the database technologies to develop the CULTNAT Heritage Repository system which consists of: (1) a unified database for all the Egyptian heritage aspects, (2) Content Management System (CMS) that helps CULTNAT researchers in creating, reading, updating and deleting data in the unified database, and (3) search engine that enables users to enquire all CULTNAT heritage documentation data.

- Geographical Information Systems (GIS): through using online mapping services: such as those presented by Google $\odot$, Yahoo $\odot$, Bing $\odot$ and Mapquest $\odot$ to display customized, clickable signs, paths and areas showing points of interest (POIs) on the map and related descriptive information.

- Mobile Apps: like Egypt Travel App that has been designed to help users getting any information that they need to plan their visits to Egypt.

In relation to the availability of AR applications within Historic Cairo, all interviewees assured that "Historic Cairo hasn't any AR applications".

\section{* Benefits of AR}

All interviewees assured that AR technology can achieve many benefits for heritage sites such as:

1. Keeping the heritage sites up to date and enhancing the value of heritage sites through adding competitive advantage.

2. AR applications can help tourists to learn in different and interactive way which enhance their experiences.

One interviewee added that "AR has the ability to add information and images about the site that don't exist in the real scene. In addition, AR has the ability of allowing tourists to recall information, as well as, introducing any additional information about any aspects in the heritage site. Therefore, AR provides visitors with the opportunity to get more out of their tours". 
Another interviewee added that "Nowadays, tourists became fond of social media and want to share their opinions and experiences through these media. Furthermore, the spread of smart phones, tablets and ipads facilitates the contact with these media. AR technology helps tourists to keep in touch with other individuals and encourage social interaction among them, as well as, attracting those individuals who previously might not have decided to visit Historic Cairo ".

3. AR technology helps visitors to see the heritage sites from a different view. As a result, the site remains interesting and attract tourists to visit it many times, because AR change the perception towards the monuments of Historic Cairo from an old and traditional dusty monuments to monuments with exciting modern technologies.

4. Historic Cairo is a heritage site with a special nature that contains numerous archaeological sites distributed in different streets and districts. This special nature makes the tourist movement from one site to another more difficult. Therefore, AR technology not only helps tourists to navigate around these sites without worrying about getting lost, but also increasing tourists' awareness of the site facilities through providing them with the information they may need about hotels, restaurants, bazaars and interesting things to do.

5. Compared to old techniques, AR has been considered less expensive.

6. AR technology can enhance the interpretation of the heritage sites, as well as, providing tourists especially youth and children- with an extra tool for education interactively and entertainment. An interviewee added that "AR has the advantage of providing tourists with more efficiency explanation through using animations".

Most interviewees concluded that all responsible authorities must do their best to attract visitors; they should not simply set back and wait.

\section{* Drawbacks of Using AR}

Although the previous benefits, AR will not appeal to everyone. Some interviewees reported that AR has few drawbacks. One interviewee stated that "the use of AR technology may be inappropriate because of some social considerations or privacy". People may look at visitors weirdly as they walk and constantly hold and point the phone around. Local people may think that tourists are filming or taking photos. Another respondent stated that "the use of AR may distract tourists from listening to the explanation of the tour guide". The same respondent urged that "AR may diminish the role of tour guide".

It must be mentioned that the vast majority of respondents were less concerned about the disadvantages of AR and such these negative comments have been only mentioned few times (only $14 \%$ of respondents). These negative aspects may be due to the modernity effect of AR system, as well as, the respondents' level of familiarity with AR. Nonetheless, most interviewees had positive attitudes toward AR and supporting the implementation of AR.

\section{* Challenges of AR in Historic Cairo}

Despite the benefits of AR for Islamic heritage sites, all interviewees agreed that there are many challenges involved with adopting AR technology.

In relation to human factors, one interviewee pointed that "the lack of knowledge and awareness towards the importance of such new technologies for heritage sites". Another interviewee added that "the major barrier to implement this unfamiliar technology is that the concerned institutions need to 
think about the importance of AR for heritage sites". Another respondent stated that "the lack of communication between those who are responsible for heritage sites and those who are responsible for technology". The same respondent added that "generally there is a lack of coordination between all responsible authorities. " Another challenge is the lack of fund. Nearly, all heritage sites suffer from insufficient financial resources which needed for installing any new technology.

In relation to technical challenges, one interviewee mentioned that "the implementation of $A R$ technology in the heritage sites is a challenge in itself" because the implementation of AR in the outdoors is more difficult than indoors -such as museums- because of many operating conditions. An interviewee added that "AR outdoor systems should bear all potential weather conditions such as: rains, heat and wind".

Another respondent added that "the display is considered the major challenge during the usage of AR in heritage sites, because most AR applications are using screen based displays and the direct sunlight may affect the image resolution, as well as, the need to sufficient light sources to overcome the darkness during the night hours". Finally, almost all interviewees agreed upon that the effectiveness of GPS is considered a great challenge. Although, the importance of GPS for tracking in AR system, it sometimes supplies errors in the given information in Egypt.

\section{Conclusion and recommendations}

This study aims to shed light on the current situation of AR implementation in Historic Cairo as an Egyptian cultural heritage site. The research attempts to understand the perspective of key organizations towards AR adoption. The literature review highlighted the definition of AR, differences between $\mathrm{AR}$ and VR, the use of AR in tourism and cultural heritage sites, benefits and challenges of AR, as well as, the need of AR for Historic Cairo.

The practical study has been conducted to achieve the research aim and clarify whether AR has been adopted in Historic Cairo -as one of the Egyptian Islamic cultural heritage sites- or not, the importance of this new technology for the Egyptian Islamic cultural heritage sites and the key challenges that facing the implementation of AR and finally provide suggestions that encourage AR implementation in Islamic cultural heritage sites especially Historic Cairo. Qualitative semi-structured interviews have been undertaken with the representatives of the key organizations to provide us with the information that increase our understanding about the current situation of AR implementation within the area of Historic Cairo.

The study findings revealed that nearly all participants appreciate the usage of this new technology for the Historic Cairo. They listed many benefits that could be achieved through the implementation of AR. This result was in line with the studies of (Sparacino, 2002; Fritz et al., 2005; Wanger et al., 2005; Kounavis et al., 2012; Linaza et al., 2012; Fino et al., 2013; Mohd et al., 2015). Participants also confirmed the importance of AR implementation within the Historic Cairo to remain competitive and keep attracting visitors. This finding comes to agree with (Han et al., 2014; Mohd et al., 2015). However, despite these benefits, the main findings of the practical study revealed that none of the Islamic cultural heritage sites in Egypt has been using AR technology. This result comes to agree with the study of (Chung et al., 2015) which confirmed that AR is still not actively and vastly used, its implementation has been slower than expected. 
The great challenges that affect the AR use and implementation within Historic Cairo can be determined in the following: the lack of knowledge and awareness of the importance of AR for heritage sites, insufficient financial resources that needed to adopt such new technologies in the Egyptian cultural heritage sites, as well as, the lack of coordination between all responsible authorities. In addition to, some technical challenges such as: GPS effectiveness that effects on tracking system, the lack of free internet connection in the Egyptian cultural heritage sites and the problems of AR displays that based on the screens of tablets and mobile phones when being used in heritage sites (an outdoor environment). These challenges are in line with the studies of (Azuma et al., 2001; Fritz et al., 2005; Kounavis et al., 2012; Abboud, 2014; Mohd et al., 2015; Cranmer et al., 2016).

Based on both the literature reviewed and the practical study, the following recommendations could be suggested:

1. One of the best ways to encourage the implementation of AR in heritage sites -especially Historic Cairo- is raising the awareness and acceptance of responsible authorities with AR. They should encourage using such new technologies to reinforce information display in Historic Cairo instead of using traditional information sources.

2. To enhance AR implementation, there is an urgent need to develop an AR project for Historic Cairo like ARCHEOGUIDE and MARCH projects. The suggested project for Historic Cairo must be developed to use AR system for providing visitors with Augmented Reality tours to explore the archaeological sites in Historic Cairo by overlaying the various types of computer generated data (e.g. audio, video, ...) on the real environment. This suggested project for Historic Cairo should include two main steps: the first step will include the design of home page which contains a research button that enables the user to find any archaeological site in Historic Cairo. By clicking on the site, different information is shown in the form of various multimedia contents such as: (text, audio, photo, video and maps). While, the second step will include the development of contents by specialists about the archaeological sites in Historic Cairo. These developed contents including information about the site such as: the founder, construction date, historical background, function of the site, as well as, the architectural and artistic description. Maps could be also used to reinforce these contents, and will help the user to get information about the areas of interest such as: hotels, restaurants and bazaars. These contents could be enhanced by audios and videos that telling the history of the selected site in the form of an interesting storyline. When the visitor points the camera of his mobile phone or tablet at any monument during his tour in Historic Cairo, all previous contents are simply emerged on his tablet or phone. These contents enable him to recognize unknown areas and discover old heritage aspects of the site in an interactive and interesting way. He can also share his experience with his friends on social media.

3. Enhancing cooperation between different authorities that are responsible for heritage sites.

4. Enhancing coordination between these authorities and those who are specialist in the field of information technology (IT) such as (Cult Nat and IT units in local ministries) to adopt AR project for the Egyptian heritage sites generally and Historic Cairo particularly.

5. To keep cultural heritage sites attractive and competitive, concerned authorities must pay more attention for the studies and researches that concerned with the usage of new technologies in cultural heritage sites. These studies provide both practitioners and academics with valuable information. 


\section{References}

- Abboud, R. (2014) . Architecture in an Age of Augmented Reality: Opportunities and Obstacles for Mobile AR in Design, Construction, and Post-Completion. National Association of Women in Construction (NAWIC), International Women's Day Scholarship Recipient 2013. Australia.

- Altinay, L. \& Paraskevas, A. (2008). Planning research in hospitality and tourism. Butterworth-Heinemann: Oxford.

- Antoniou, J. (2009). Historic Cairo: A walk through the Islamic city. The American university in Cairo press. $5^{\text {th }}$ edition. Egypt.

- Anuar, F. I. (2013). Smartphone-Mediated Tourist Experiences: Understanding the Influence of Augmented Reality (AR) Applications in Tourism. Ph.D. Thesis. Texas A\&M University.

- Aziz, K. Ab. \& Siang, T. G. (2014). Virtual Reality and Augmented Reality Combination as a Holistic Application for Heritage Preservation in the UNESCO World Heritage Site of Melaka. International Journal of Social Science and Humanity, 4(5), 333-338.

- Azuma, R. T. (1997). A survey of augmented reality. Presence, Teleoperators and Virtual Environment, 6(4), 355-385.

- Azuma, R., Baillot, Y., Behringer, R., Feiner, S., Julier, S. \& MacIntyre, B. (2001). Recent Advances in Augmented Reality. Journal of IEEE Computer Graphics and Applications archive, 21(6), 34-47.

- Buhalis, D., \& Amaranggana, A. (2014). Smart tourism destinations, In Z. Xiang \& I. Tussyadiah (eds.), Information and communication technologies in tourism, pp. 553-564, Dublin: Springer.

- Butchart, B. (2011). Augmented reality for smartphones: A guide for developers and content publishers. Techwatch report, JISC observatory. University of Bath. Retrieved 20 August 2016 from:

○ http://opus.bath.ac.uk/34847/1/AR Smartphone_final.pdf.

- Casella, G. \& Coelho, M. (2013). Augmented heritage - Situating augmented reality mobile apps in cultural heritage communication: proceeding of the 2013 International Conference on Information Systems and Design of Communication, 138-140. Lisbon, Portugal. New York: ACM.

- Choi, G. R. \& Choi, H. H., (2014). Proposal of the Promotional Video Design Model of Culture Contents, using 3D Image Moving Technique: Applying the Augmented Reality and E-museum Concepts. International Journal of Smart Home, 8(6), 107-118.

- Choudary, O., Charvillat, V., Grigoras, R., \& Gudjos, P. (2009). MARCH: Mobile augmented reality for cultural heritage. Proceedings of the 17th international conference on Multimedia, 1023-1024. New York, USA. New York: ACM.

- Chung, N., Han, H. \& Joann, J. (2015). Tourists' intention to visit destination: Role of augmented reality applications for heritage site. Computers in Human Behavior, 50, 588-599

- Cranmer, E., Jung, T., tom Dieck, M. C., \& Miller, A. (2016). Understanding the Acceptance of Augmented Reality at an Organisational Level: The Case of Geevor Tin Mine Museum. Information and Communication Technologies in Tourism, 637- 650. Springer International Publishing

- Deliyiannis, I. \& Papaioannou, G. (2014): Augmented Reality for Archaeological Environments on Mobile Devices: A Novel Open Framework, University of the Aegean, Mediterranean Archaeology \& Archaeometry, 14(4), 1-10.

- Fino, E., Martin-Gutierrez, J., Fernandez, M. \& Davara, E. (2013). Interactive Tourist Guide: Connecting Web 2.0, Augmented Reality and QR Codes. Procedia Computer Science, 25, 338-344.

- $\quad$ Fritz, F., Superregui, A. \& Linaza, M. (2005). Enhancing Cultural tourism experiences with Augmented Reality Technologies. Proceedings of 6TH International Symposium on Virtual Reality, Archaeology and Cultural Heritage (VAST). San Sebastian, Spain: The Eurographics Association.

- Garcia-Crespo, A., Chamizon, J., Rivera, I., Mencke, M., Colomo-Palacios, R. \& Gomez-Berbis, J. (2009). SPETA: Social Pervasive e-Tourism Advisor. Telematics and informatics, 26(3), 306- 315.

- Guttentag, D. A. (2010). Virtual reality: applications and implications for tourism. Tourism Management, 31(5), 637-651.

- Han, D. I., Jung, T., \& Gibson, A. (2014). Dublin AR: Implementing augmented reality in tourism. In Z. Xiang, \& I. Tussyadiah (Eds.), Information and communication technologies in tourism, pp. 511-523. Vienna: Springer.

- Höllerer, T.H., \& Feiner, S.K. (2004). Mobile augmented reality. In H. Karimi \& A. Hammad (Eds.), Telegeoinformatics: Location-based computing and services. London: Taylor \& Francis Books Ltd.

- Hyun, M. Y., Lee, S., \& Hu, C. (2009). Mobile-mediated virtual experience in tourism: Concept, typology and applications. Journal of Vacation Marketing, 15(2), 149-164. 
- Kounavis, C. D., Kasimati, A. E., \& Zamani, E. D. (2012). Enhancing the Tourism Experience through Mobile Augmented Reality: Challenges and Prospects. International Journal of Engineering Business Management, 4(10), 1-6.

- Kretschmer, U., Coors, V., Spierling, U., Grasbon, D., Schneider, K., Rojas, I., \& Malaka, R. (2001). Meeting the spirit of history. Proceedings of the 2001 conference on Virtual reality, archeology, and cultural heritage (VAST), 141-152. Glyfada, Athens, Greece. Eurographics. New York: ACM.

- Kumar, R. (2014). Research Methodology. A step by step guide for beginners. Sage Publications: London.

- Leue, M. C., tom Dieck, D., \& Jung, T. (2014). A theoretical model of augmented reality acceptance. E-Review of Tourism Research, 5, 1-5.

- Linaza, M. T., Marimón, D., Carrasco, P., Álvarez, R., Montesa, J., Aguilar, S. R., \& Diez, G. (2012). Evaluation of Mobile Augmented Reality Applications for Tourism Destinations In M. Fuchs et al. (Eds.), Information and Communication Technologies in Tourism, pp. 260-271. Vienna: Springer.

- Milgram, p., Takemura, h., Utsumi, a. \& Kishino, f. (1994) Augmented Reality: A class of displays on the reality-virtuality continuum. Proceedings of the SPIE: Telemanipulator and Telepresence Technologies, 2351, 282-292.

- Mohd, N. S., Ismail, H. N., \& Halim, N. A. (2015). Mobile Augmented Reality: A Tool for Effective Tourism Interpretation in Enhancing Tourist Experience at Urban Tourism Destination. International Journal of Built Environment And Sustainability (IJBES), 2(3), 237-244.

- Pang, Y., Nee, A., Ong, S., Yuan, M., \& Youcef-Toumi, K. (2006). Assembly feature design in an augmented reality environment. Assembly Automation, 26(1), 34-43.

- Pendit, U. C. \& Zaibon, S. B. (2014). Enjoyable Informal Learning in Cultural Heritage Site using Mobile Augmented Reality: A Conceptual Model, Journal of Advances in Science and Technology, 2(3), 93-106.

- Pendit, U. C., Zaibon, S. B. \& Abubakar, J. A. (2014). Mobile Augmented Reality for Enjoyable Informal Learning in Cultural Heritage Site, International Journal of Computer Applications (0975 - 8887), 92(14), 19-26.

- Rabbi, I., Ullah, S., Richard, P., Otmane, S., \& Mallem, M. (2013). A Survey on Augmented Reality Challenges and Tracking. Acta Graphica, 24(1-2), 29-46.

- Seo, B. K., Kim, K., \& Park, J. I. (2011). Augmented reality-based on-site tour guide: a study in Gyeongbokgung. In Computer Vision-ACCV 2010 Workshops, 276-285. Berlin Heidelberg: Springer.

- Sparacino F. (2002). The museum wearable: real time sensor driven understanding of visitors' interests for personalized visually augmented museum experiences. Proceedings of the Museums and the Web, 1-27. Boston MA.

- tom Dieck, M.C. \& Jung, T. (2015). A theoretical model of mobile augmented reality acceptance in urban heritage tourism. Current Issues in Tourism, 18, 1-21.

- Van Krevelen, D.W.F. \& Poelman, R. (2010). A Survey of Augmented Reality Technologies, Applications and Limitations. The International Journal of Virtual Reality, 9(2),1-20

- Vlahakis, V., Karigiannis, J., Tsotros, M., Gounaris, M., Almeida, L., Stricker, D., Gleue, T., Ioannis, T. C., Carlucci, R. \& Ioannidis, N. (2001). Archeoguide: First Results of an Augmented Reality Mobile Computing System in Cultural Heritage Sites. Proceedings of the 2001 Conference on Virtual Reality, Archeology, and Cultural Heritage (VAST), 131-140, Glyfada, Athens, Greece. Eurographics. New York: ACM.

- Wagner, D., Pintaric, T., Ledermann, F., \& Schmalstieg, D. (2005). Towards Massively Multi-User Augmented Reality on Handheld Devices. Proceedings of the 3rd International Conference on Pervasive Computing, 208219. Munich, Germany.

- Warner, N. (2005). The monuments of Historic Cairo: A map and descriptive catalogue. The American university in Cairo press. Egypt.

- Yovcheva, Z., Buhalis, D., \& Gatzidis, C. (2013). Engineering Augmented Tourism Experiences. In L. Cantoni \& Z. Xiang (Eds.), Information and Communication Technologies in Tourism, pp. 24-36. Heidelberg: Springer.

- Zaibon, S. B., Pendit, U. C. \& Abubakar, J. A. (2015). Applicability of mobile augmented reality usage at Melaka cultural heritage sites. Proceedings of The 5th International Conference on Computing and Informatics (ICOCI). 235-240, Istanbul, Turkey.

- Zoellner, M., Stricker, D., Bleser, G., \& Pastarmov, Y. (2007). iTACITUS - Novel Interaction and Tracking Paradigms for Mobile AR. In D. Arnold (Ed.), The European Research Network of Excellence in Open Cultural Heritage (EPOCH), pp. 110-117. Budapest: Archaeolingua. http://whc.unesco.org/ accessed on: 7/9/2016 